\title{
"Dried alginate-entrapped enzymes (DALGEEs) and their application to the production of fructooligosaccharides"
}

Authors: L. Fernandez-Arrojo, B. Rodriguez-Colinas, P. Gutierrez-Alonso, M. Fernandez-Lobato, M. Alcalde, A.O. Ballesteros and F.J. Plou

Published in:

Process Biochemistry $\underline{48}$, 677-682 (2013)

http://dx.doi.org/10.1016/j.procbio.2013.02.015 


\section{Dried alginate-entrapped enzymes (DALGEEs) and}

\section{their application to the production of}

\section{fructooligosaccharides}

Lucia Fernandez-Arrojo ${ }^{a}$, Barbara Rodriguez-Colinasa , Patricia Gutierrez-

Alonso $^{\text {b }}$ Maria Fernandez-Lobato ${ }^{\text {, }}$ Miguel Alcalde ${ }^{a}$,

Antonio O. Ballesteros ${ }^{\mathrm{a}}$ and Francisco J. Plou ${ }^{\mathrm{a}, *}$

a Instituto de Catálisis y Petroleoquímica, CSIC, 28049 Madrid, Spain

b Centro de Biología Molecular Severo Ochoa, UAM-CSIC, 28049 Madrid, Spain

Corresponding author: Francisco J. Plou, Departamento de Biocatálisis, Instituto de Catálisis y Petroleoquímica, CSIC, Marie Curie 2, 28049 Madrid, Spain. Phone: +34-91-5854869. Fax: +34-91-5854760. E-mail: fplou@icp.csic.es. URL: http://www.icp.csic.es/abgroup 


\section{ABSTRACT}

2 A modification of the classical calcium alginate enzyme entrapment technique is

3 described aiming to overcome some of the limitations of the former gel-based

4 biocatalysts. DALGEEs (Dried ALGinate Entrapped Enzymes) were obtained 5 dehydrating calcium alginate gel beads containing entrapped enzymes. A

6 fructosyltransferase from Aspergillus aculeatus, present in Pectinex Ultra SP- $\mathrm{L}_{\llcorner}$was

7 entrapped using this technique. The resulting DALGEEs were successfully tested 8 both operating batchwise and in a continuous fixed-bed reactor for 9 fructooligosacharide (FOS) synthesis from sucrose. Interestingly, DALGEEs did

10 not re-swell upon incubation in concentrated $(600 \mathrm{~g} / \mathrm{L})$ sucrose solutions, probably

11 due to the lowered water activity $\left(\mathrm{a}_{\mathrm{w}}\right)$ of such media. Confocal laser scanning 12 microscopy of DALGEEs revealed that the enzyme molecules accumulated

13 preferably in the shell of the particles. DALGEEs showed an approximately 30 -fold

14 higher volumetric activity $(300 \mathrm{U} / \mathrm{mL})$ compared with the calcium alginate gel

15 beads. Moreover, a significant enhancement (40-fold) of the space-time-yield of

16 fixed-bed bioreactors was observed when using DALGEEs as biocatalyst

17 compared with gel beads $(4030 \mathrm{~g} /$ day $\cdot \mathrm{L}$ of FOS $v s .103 \mathrm{~g} /$ day $\cdot \mathrm{L})$. The operational

18 stability of fixed-bed reactors packed with DALGEEs was extraordinary, providing

19 a nearly constant FOS composition of the outlet during at least $700 \mathrm{~h}$. It was also

20 noticeable their resistance against microbial attack, even after long periods of

21 storage at room temperature. The DALGEEs immobilization strategy may also be 
1 useful for other biotransformations, in particular when they take place in low $\mathrm{a}_{\mathrm{w}}$ 2 media.

4 Keywords: enzyme immobilisation; entrapment; hydrogels; glycosidases; 5 fructooligosaccharides; food oligosaccharides. 


\section{1. INTRODUCTION}

Compared with covalent immobilization methods, enzyme entrapment in

3 alginate beads is a low-cost approach that does not exert any chemical

4 modification to the protein structure. Alginate is a highly negatively charged

5 polysaccharide extracted from brown algae that forms rigid gel-like structures in

6 presence of divalent cations. Enzyme entrapment in alginate is straightforwardly

7 accomplished under mild conditions, providing outstanding activity recoveries

8 and easy diffusion of substrates and products through the matrix pores [1-3].

9 Typically, alginate entrapment is widely applied to the immobilisation of living 10 cells $[4 ; 5]$.

Alginate gel-based biocatalysts present several practical limitations such as a

12 low volumetric activity and microbial contamination of the beads, even in the

13 refrigerator, due to their high content of water and carbon [6;7]. Undesired enzyme

14 leakage from the gel beads due to the size of the pores [6] is another typical

15 disadvantage of alginate entrapment method. The diffusion out of the beads can be

16 minimised by increasing alginate concentration and/or mannuronic

17 (M)/guluronic (G) acid ratio, as well as decreasing the $\mathrm{pH}$ [8]. Among other

18 strategies to avoid protein leakage, enzymes can be cross-linked with

19 glutaraldehyde [9] or bound to a carrier such as activated coal [10] prior to the

20 entrapment process. In another recent twist, the crosslinking of alginate with

21 glutaraldehyde has been also explored [11;12]. Nevertheless, the complete removal 
1 of toxic crosslinking chemicals is difficult and thus may be inappropriate for its

2 application in food processing industries [13].

In this work, we have tackled some of the hurdles of calcium alginate

4 immobilization method by applying a drying process to the gel beads. It is well

5 reported that drying of alginate beads is widely applied in the delivery of drugs

6 and enzymes (esp. in the detergents industry), since the beads, in contact with

7 water, swell to their original size releasing the bioactive molecules [14;15]. Our

8 hypothesis was that dried-alginate beads should not re-swell in a medium with

9 low water activity $\left(\mathrm{a}_{\mathrm{w}}\right)$ such as highly concentrated sugar solutions. In addition,

10 the strategy of drying the calcium alginate gel-based biocatalyst could lead to an

11 increased volumetric activity and thus a lower reactor volume to obtain a given

12 productivity.

13 For this purpose, we selected the fructosyltransferase from Aspergillus

14 aculeatus [16] and the resulting immobilized biocatalyst was characterized and

15 tested in batch and continuous reactors for the production of

16 fructooligosaccharides (FOS). FOS are fructose oligomers with a terminal glucose

17 group in which 2-4 fructofuranosyl moieties are linked by different bonds (Fig. 1)

18 [17-19]. Commercial FOS are mainly composed of 1-kestose, nystose and ${ }^{1} \mathrm{~F}-$

19 fructofuranosylnystose [20]. They are produced at multi-ton scale from

20 concentrated sucrose solutions using fungal transfructosylating enzymes such as

21 those from Aspergillus niger, Aspergillus oryzae and Aureobasidium pullulans [21;22]. 
1 FOS are non-cariogenic ingredients, have a sweetness of $40-60 \%$ relative to sucrose,

2 and exhibit prebiotic properties [23;24].

An effective immobilisation method of fructosyltransferases is highly

4 desired as it would allow a continuous FOS production process, the reuse of the

5 biocatalyst and the reduction of the total costs for industrial settings [25-27]. In

6 addition, immobilisation often protects enzymes from inactivation at extreme $\mathrm{pH}$,

7 high temperatures or organic solvents [28;29]. In this work, the dried alginate

8 biocatalysts were studied characterised, and their advantages over the classical

9 alginate gel beads (volumetric activity, stability and space-time-yield) were

10 highlighted. 


\section{2. MATERIALS AND METHODS}

2 2.1. Materials.

3 Pectinex Ultra SP-L (batch no. KRN05409), a preparation from Aspergillus aculeatus

4 used in fruit juice processing that contains pectinolytic, cellulolytic and

5 fructosyltransferase activities [16], was kindly donated by Novozymes A/S

6 (Denmark). Sodium alginate SG300 was obtained from Degussa Texturant

7 Systems, Spain. Sodium alginate Algogel 6021 and Algogel 3021 were kindly

8 donated by Cargill Iberica, Spain. Sucrose, glucose and fructose were from Merck.

9 1-Kestose and nystose were from TCI Europe. 1F-Fructosyl-nystose was from

10 Megazyme (Ireland). All other reagents were of the highest available purity.

12 2.2. Preparation and characterisation of dried alginate-entrapped enzymes 13 (DALGEEs).

14 The gel beads were prepared by ionotropic gelation as described elsewhere [1] 15 with some variations. A $4 \%(\mathrm{w} / \mathrm{v})$ sodium alginate solution was prepared in

16 distilled water and stirred until a homogeneous clear solution was observed. The

17 solution was let to settle for 2 hours in order to eliminate all air bubbles. The

18 alginate solution was then gently mixed in a ratio $1: 1(w: w)$ with the enzyme

19 solution (Pectinex Ultra SP-L diluted 1:2 v/v with $10 \mathrm{mM}$ sodium acetate buffer,

$20 \mathrm{pH}$ 5.6). The resulting enzyme-alginate mixture was dropped with the help of a

21 peristaltic pump (P-1, GE Healthcare) onto a $0.2 \mathrm{M} \mathrm{CaCl}_{2}$ solution in sodium

22 acetate buffer ( $\mathrm{pH} 5.6,10 \mathrm{mM}$ ). A pipette tip was used at the outlet of the pump

23 and placed $5 \mathrm{~cm}$ over the $\mathrm{CaCl}_{2}$ solution. The drops instantly formed gel beads in 
1 contact with the $\mathrm{CaCl}_{2}$ solution, which was maintained under magnetic stirring at

$2100 \mathrm{rpm}$. The beads were hardened in the $\mathrm{CaCl}_{2}$ solution for 20 min with mild

3 agitation. The diameter of the beads obtained was around $3 \mathrm{~mm}$. The gel beads

4 were then separated from the solution and washed twice with $250 \mathrm{~mL}$ of sodium

5 acetate ( $\mathrm{pH} 5.6,10 \mathrm{mM})$ for 15 min under mild agitation. The gel beads obtained as

6 described above were dehydrated by air flow or controlled evaporation at $35^{\circ} \mathrm{C}$

7 until the size of the particles remained constant. The resulting beads were called

8 DALGEEs (Dried ALGinate Entrapped Enzymes).

\subsubsection{Confocal microscopy.}

11 Protein distribution in DALGEE particles was studied using confocal fluorescence

12 microscopy. Before immobilisation, proteins present in Pectinex-Ultra SP-L were

13 labelled with fluorescein isothiocyanate (FITC), a fluorophore that chemically

14 attaches to amino groups in proteins [30]. Pectinex Ultra SP-L was diluted 1:2 (v/v)

15 in $0.1 \mathrm{M} \mathrm{Na}_{2} \mathrm{CO}_{3}$. Then, FITC dissolved in $\mathrm{N}, \mathrm{N}$-dimethylformamide was added to

16 the protein solution in a ratio of $5 \mu \mathrm{g}$ of FITC per milligram of protein [31]. The

17 unbound FITC was removed using a pre-packed PD-10 column (Amersham

18 Biosciences). The FITC-labelled protein sample was diluted 1:2, 1:100 and 1:1000

19 (v/v) with $10 \mathrm{mM}$ acetate buffer ( $\mathrm{pH}$ 5.6) before the immobilisation in calcium

20 alginate and further drying. The resultant DALGEEs were analysed with a

21 confocal laser scanning microscope (Leica, model TCS SP2-AOBS). An oil

22 immersion objective $(40.0 \times 1.25)$ was used for all measurements and the pinhole

23 aperture was set to 1.50 Airy $(122 \mu \mathrm{m})$. The excitation wavelength was $488 \mathrm{~nm}$ and 
1 the emission was collected at 500-550 nm, with the corresponding filters.

2 Micrographs were taken at different plane depths. The exposure of the

3 micrographs was adjusted using the software for image processing.

4

$5 \quad$ 2.2.2 Porosimetry.

6 The specific surface area $\left(\mathrm{S}_{\mathrm{BET}}\right)$ of the DALGEEs was determined from analysis of

7 nitrogen adsorption isotherms at $-196^{\circ} \mathrm{C}$ using a Micromeritics ASAP 2010

8 equipment. The samples were previously degassed at $100^{\circ} \mathrm{C}$ for $12 \mathrm{~h}$ to a residual

9 vacuum of $5 \times 10^{-3}$ Torr in order to remove any loosely held adsorbed species.

$11 \quad$ 2.2.3. Water content.

12 A volumetric Karl-Fisher titrator (Mettler Toledo, model DL31) was used for 13 measuring the water content of DALGEEs, employing Hydranal composite 5 as 14 reagent.

16 2.2.4. Scanning electron microscopy

17 The DALGEEs were mounted on aluminium SEM stubs and sputter-coated with a

18 thin layer of gold at completed Torr vacuum. Samples were examined by scanning

19 electron microscopy using an XL3 microscope (Philips) at an acceleration potential 20 of $20 \mathrm{kV}$. 
1 The enzymatic activity towards sucrose was determined at $60^{\circ} \mathrm{C}$ in $0.2 \mathrm{M}$ sodium

2 acetate buffer ( $\mathrm{pH}$ 5.6) by measuring the release of reducing sugars from $100 \mathrm{~g} / \mathrm{L}$

3 sucrose solution using the dinitrosalicylic acid (DNS) method [32]. The assay was

4 adapted to 96-well microplates as described in our previous work [25]. One unit

$5(U)$ of activity was defined as that catalyzing the formation of $1 \mu \mathrm{mol}$ of reducing

6 sugars per minute under the above conditions. The activity of the immobilised

7 biocatalysts was determined incubating in an Eppendorf tube approx. $50 \mathrm{mg}$ of

8 alginate beads with $0.45 \mathrm{~mL}$ of $100 \mathrm{~g} / \mathrm{L}$ sucrose solution in $0.2 \mathrm{M}$ sodium acetate

9 buffer ( $\mathrm{pH}$ 5.6). The mixture was maintained at $60^{\circ} \mathrm{C}$ and $600 \mathrm{rpm}$ for $20 \mathrm{~min}$ in a

10 Vortemp 56 incubator (Labnet). A $200 \mu \mathrm{L}$ sample of the supernatant was

11 withdrawn and submerged for $10 \mathrm{~min}$ in a water bath at $95^{\circ} \mathrm{C}$, in order to

12 inactivate the possible lixiviated enzyme. Then, $50 \mu \mathrm{L}$ of this sample were

13 transferred to one of the wells of the microplate, and the concentration of reducing

14 sugars was measured as described above.

\section{2.4. Operational stability of DALGEEs in batch reactor}

17 DALGEEs (approx. $10 \mathrm{mg}$ ) were incubated with $250 \mu \mathrm{L}$ of $600 \mathrm{~g} / \mathrm{L}$ sucrose solution

18 at $35^{\circ} \mathrm{C}$ and $900 \mathrm{rpm}$ in a Vortemp 56 incubator (Labnet). After 20 minutes, the

19 DALGEEs were separated from the reaction medium. The supernatant was

20 incubated at $95^{\circ} \mathrm{C}$ for $10 \mathrm{~min}$ in a water bath (in order to inactivate any possible

21 lixiviated enzyme) and the content of reducing sugars was determined using the

22 DNS method. The DALGEEs were washed twice with a cooled $\left(4^{\circ} \mathrm{C}\right)$ sucrose

23 solution using high vortex agitation for 30 seconds each wash. A total of 13 
1 reaction cycles, with washes in between, were performed to evaluate the

2 operational stability of DALGEEs.

4 2.5. Operational stability of DALGEEs in a continuous fixed-bed reactor

5 DALGEEs containing the entrapped fructosyltransferase were packed in a

6 HiTrap ${ }^{\mathrm{TM}}$ column with $1 \mathrm{~mL}$ of total volume $(7 \times 25 \mathrm{~mm}$, GE Healthcare). The inlet

7 of the column was connected to an isocratic pump with dual reciprocating pistons

8 (model 515, Waters), in order to precisely control the flow of the feeding solution

9 to the bioreactor $(600 \mathrm{~g} / \mathrm{L}$ sucrose in $0.2 \mathrm{M}$ sodium acetate buffer, $\mathrm{pH}$ 5.6). Both the

10 bioreactor and the feeding solution were maintained at $35^{\circ} \mathrm{C}$ in an Ovan chamber

11 incubator (Lovango). At different times, samples were taken at the outlet stream of

12 the bioreactor and analysed by HPLC. When using gel beads, a column XK 16/20

13 (GE Healthcare) with $30 \mathrm{~mL}$ of total volume was used.

\subsection{HPLC analysis}

16 The analysis and quantification of the different carbohydrates present in the

17 transfructosylation reactions was carried out by HPLC with a quaternary pump

18 (Delta 600, Waters) coupled to a $4.6 \times 250 \mathrm{~mm}$ Luna- $\mathrm{NH}_{2}$ column $(5 \mu \mathrm{m}, 100 \AA$ )

19 from Phenomenex. Detection was performed using an evaporative light scattering

20 detector DDL-31 (Eurosep) equilibrated at $85^{\circ} \mathrm{C}$. Acetonitrile/water 75:25 (v/v),

21 degassed with helium, was used as mobile phase at $0.9 \mathrm{~mL} / \mathrm{min}$ for $3 \mathrm{~min}$. Then, a

22 gradient from this eluent to acetonitrile/water 70:30 (v/v) was performed in 1

$23 \mathrm{~min}$, and held for $2 \mathrm{~min}$. A new gradient to acetonitrile/water 60:40 (v/v) was 
1 performed in $2 \mathrm{~min}$ and held for $6 \mathrm{~min}$. Total analysis time was $14 \mathrm{~min}$. The

2 column temperature was kept constant at $25^{\circ} \mathrm{C}$. The data obtained were analysed 3 using the Millennium Software.

4

5 2.7. Water activity

6 Water activity of sugar solutions was determined using a humidity and 7 temperature digital indicator Thermoconstanter TH200 (Novasina, Switzerland).

8 The humidity sensor was calibrated with control saturated salts solutions of 9 different $\mathrm{a}_{\mathrm{w}}$ values $(\mathrm{LiCl}, 0.11$; potassium acetate, $0.22 ; \mathrm{NaBr}, 0.57 ; \mathrm{NaCl}, 0.75$; $\left.10 \mathrm{~K}_{2} \mathrm{Cr}_{2} \mathrm{O}_{7}, 0.98\right)$ at $25^{\circ} \mathrm{C}$. 


\section{3. RESULTS AND DISCUSSION}

\section{3.1. Preparation and characterisation of dried alginate-entrapped enzymes}

(DALGEEs)

Fructosyltransferase activity from A. aculeatus, present in Pectinex Ultra SP-

5 L [16;33], was entrapped in calcium alginate beads using different commercial

6 sodium alginates (SG300, Algogel 6021 and Algogel 3021) and their immobilisation

7 yields were compared (Table 1). The immobilized enzymatic activity of the

8 alginate beads was determined indirectly by measuring the initial activity of the

9 solution before gelation and the activity present in the $\mathrm{CaCl}_{2}$ and washing

10 solutions. The value calculated was considered as the theoretical immobilised

11 activity. The main contribution to the loss of activity occurs while the drop is not

12 fully gelled to form the bead [34]. Table 1 shows that sodium alginate SG300 was

13 the most adequate for our purpose, probably due to an optimal

14 mannuronic/guluronic acid ratio, with an immobilisation yield close to 50\%. This

15 value was also in accordance with the total protein immobilisation yield $(47 \%)$

16 measured by the Bradford assay. Initial protein concentration in Pectinex

17 preparation was approx. $17 \mathrm{mg} / \mathrm{ml}$ and fructosyltransferase accounted for only

$180.4 \%$ of total protein [16]. Theoretical immobilisation yields in the range $40-80 \%$ are

19 usually reported $[1 ; 9 ; 11 ; 13]$ and, therefore, the SG300 alginate was selected for

20 further experiments.

The so-called apparent activity (experimental) of the immobilised

22 biocatalysts, which takes into account mass transfer and diffusional restrictions 
1 [35], was measured using 3 gel-beads (approx. $50 \mathrm{mg}$ ) and $100 \mathrm{~g} / \mathrm{L}$ sucrose. The

2 volumetric apparent activity of the SG300 gel-based biocatalyst was $10 \mathrm{U} / \mathrm{mL}$,

3 which is nearly 4-fold lower than the theoretical value. The difference between

4 theoretical and apparent activities seems to be related with the mass transfer of

5 substrates and products within the alginate matrix.

We performed the drying process of the calcium alginate gel beads and the

7 resulting biocatalysts, with a crystalline appearance, were called DALGEEs (Dried

8 ALGinate Entrapped Enzymes). The size of the alginate beads was significantly

9 reduced, from $3 \mathrm{~mm}$ to less than $1 \mathrm{~mm}$ upon drying, which accounted for a

10 volume reduction of approx. 96\% (considering the beads as perfect spheres). The

11 images obtained by scanning electron microscopy of the DALGEE particles are

12 shown in Fig. 2. Beads were nearly spherical and quite homogeneous in size,

13 showing a rough surface. Santagapita et al. reported that roughness or smoothness

14 is affected both by the beads composition and drying method [36].

A crucial point for the applicability of DALGEEs was to analyse if they

16 rehydrated when they were submerged in the sugar solution, as swelling may be

17 accompanied by enzyme leakage. Fig. 3 shows that DALGEEs rehydrate in buffer

18 solution. In contrast, DALGEEs beads maintain its initial size after 1 day

19 incubation in $600 \mathrm{~g} / \mathrm{L}$ sucrose. This fact seems to be related with the decrease of

20 water activity $\left(\mathrm{a}_{\mathrm{w}}\right)$ caused by sucrose [37]. This property is important since many

21 chemical, enzymatic and microbiological processes are dependent on the

22 availability of water [38;39]. The DALGEEs swell very slightly when they are in 
1 contact with a concentrated sucrose solution; this smooth swelling may facilitate

2 the contact between the enzyme molecules and the substrates. We observed that a

$3600 \mathrm{~g} / \mathrm{L}$ sucrose solution lowers the $\mathrm{a}_{\mathrm{w}}$ of water from 1.0 to 0.97 ; this small change

4 is enough to prevent DALGEEs from recovering their initial size. When increasing

5 sucrose concentration up to $950 \mathrm{~g} / \mathrm{L}$, the $\mathrm{a}_{\mathrm{w}}$ diminishes to a value of 0.87 .

6 However, the swelling process may be also influenced by the M/G ratio of the

7 alginate and/or the drying method.

8 The apparent enzymatic activity of DALGEEs containing

9 fructosyltransferase from A. aculeatus was $300 \mathrm{U} / \mathrm{mL}$, which is 30 -fold higher than

10 that measured for the gel beads. The textural studies revealed the low porosity of

11 this material, with a BET area of $7.6 \mathrm{~m}^{2} / \mathrm{g}$ and a total pore volume of $0.072 \mathrm{~cm}^{3} / \mathrm{g}$,

12 measured from the adsorption nitrogen isotherms. The water content of

13 DALGEEs, determined by the Karl Fisher assay, was of only $1.5 \%$ (w/w).

The distribution of immobilised FITC-labelled proteins in DALGEEs was

15 studied by fluorescence confocal microscopy. Although fluorescence was found

16 throughout the whole volume of the beads, a clear preferential accumulation of the

17 enzyme in the shell of the particle was observed when lowering the exposure of

18 the emission signal (Fig 4A). This result is in accordance with the expected

19 hypothetical drying process, as it occurs from the outer to the inner layers thus

20 enriching the beads with protein in the external layers (Fig. 4B) [40].

\section{3.2. FOS synthesis in batch reactor with fructosyltransferase in DALGEEs}


The reuse of DALGEEs was studied in a batch reactor measuring the activity

2 of the beads in a sequence of reaction cycles. Fig. 5 illustrates the operational

3 stability of the DALGEEs in 13 successive reaction cycles of 20 min each. As it is

4 shown, the operational stability of DALGEE biocatalysts was very satisfactory.

5 This behaviour was probably related with the fact that DALGEEs do not swell in

6 concentrated sucrose solution and thus the enzyme leakage is minimised.

8 3.3. FOS synthesis in continuous fixed-bed bioreactors with fructosyltransferase

9 in DALGEEs

10 A fixed-bead reactor of small volume $(1 \mathrm{~mL})$ was packed with the

11 DALGEEs. The operation of the continuous reactor for FOS synthesis was assayed

12 at $0.01 \mathrm{~mL} / \mathrm{min}$ and $35^{\circ} \mathrm{C}$. The bioreactor was operated continuously for $700 \mathrm{~h}$

13 during which samples were taken and analysed by HPLC. As shown in Fig. 6, the

14 composition of the outlet was nearly constant at least during $700 \mathrm{~h}$, with an

15 average FOS concentration of $275 \mathrm{~g} / \mathrm{L}$, which indicated an optimal operational

16 stability of the DALGEEs biocatalysts. The composition of the outlet was

17 approximately as follows: $175 \mathrm{~g} / \mathrm{L}$ glucose, $148 \mathrm{~g} / \mathrm{L}$ sucrose, $140 \mathrm{~g} / \mathrm{L}$ 1-kestose,

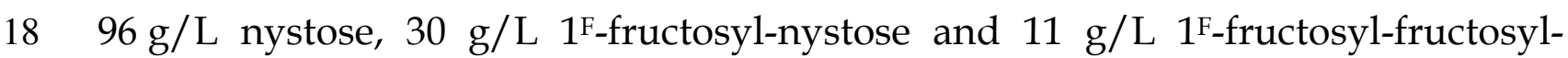

19 nystose. Considering the volume of the bioreactor and the mean concentration of

20 total FOS measured at the outlet, the space-time yield was approx. $4030 \mathrm{~g}$ FOS/

21 day $\cdot \mathrm{L}$. 
The above space-time yield was compared with that of a $25 \mathrm{~mL}$ fixed-bed

2 reactor packed with the calcium alginate gel beads, which was also operated in

3 continuous mode, at $35^{\circ} \mathrm{C}$ and with a flow rate of $0.01 \mathrm{~mL} / \mathrm{min}$. Samples at the

4 outlet of the column were analysed by HPLC. The sucrose conversion reached

5 with this system was $67 \%$, and the space-time yield was $103 \mathrm{~g}$ FOS/ day $\cdot$ L, which

6 is about 40 -fold lower than that determined for a reactor packed with DALGEEs.

7 The fructooligosacharide composition obtained from enzymatic

8 transfructosylation is highly dependent on the reaction time [25], which is

9 proportional to the residence time in a continuous reactor. The FOS composition

10 was therefore studied operating the reactor at different flow rates in order to

11 control the residence time. The results of this study (Fig. 7) showed that high

12 residence times led to a final FOS product enriched in tetra- and

13 pentaoligosaccharides, whereas low residence times yielded to a trisaccharide-

14 enriched FOS mixture. The specific effects of prebiotic oligosaccharides depend,

15 among other factors, on their degree of polymerization [18;41;42], so it is

16 interesting to control the FOS distribution varying the flow rate of the fixed-bed

17 reactor. The study also revealed that an increase of the residence time was

18 translated into higher sucrose conversion values, achieving a maximum value of

$1991 \%$. Elsewhere, the extraordinary operational stability of DALGEEs biocatalysts

20 in continuous fixed-bed reactors ensures a product with a constant FOS

21 composition.

This immobilization method may also be suitable for other biotechnological

23 processes, in particular those involving the transformation of carbohydrates. 
1 Indeed, we have also applied the DALGEEs technology to obtain glucose/fructose

2 syrups using a $\beta$-fructofuranosidase from Rhodotorula dairensis [43], to convert

3 inulin into fermentable sugars using an inulinase, and for galactooligosaccharides

4 synthesis using a $\beta$-galactosidase (data not shown).

\section{CONCLUSIONS}

The methodological simplicity for the preparation of DALGEEs and the low

8 cost of the required materials make this process attractive for its application in

9 large-scale FOS synthesis. The drying process of the gel beads resulted in particles

10 with crystalline appearance and increased volumetric activity (30-fold) compared

11 with the corresponding gel-based biocatalysts. In addition, its storage stability

12 (absence of microbial growth compared with the hydrated beads), operational

13 stability and no swelling when used in low $\mathrm{a}_{\mathrm{w}}$ media (e.g. concentrated sucrose

14 solutions) offer excellent perspectives for applications in biotransformations.

16 ACKNOWLEDGEMENTS

We thank Fernando Gonzalez (Centro de Investigaciones Biologicas, CSIC)

18 for confocal microscopy support. We thank Ramiro Martínez (Novozymes A/S,

19 Madrid, Spain) for supplying Pectinex and for useful suggestions. Projects

20 BIO2010-20508-C04-01 and BIO2010-20508-C04-04 from Spanish Ministry of

21 Science and Innovation supported this research. We thank Fundacion Ramon

22 Areces by the institutional Grant to the Centro de Biología Molecular Severo 
1 Ochoa. B.R.C was supported by a fellowship from the Spanish Ministry of Science

2 and Innovation (FPI program).

3 


\section{REFERENCES}

2 [1] Gomez de Segura A, Alcalde M, Bernabe M, Ballesteros A, Plou FJ. Synthesis of 3 methyl alpha-D-glucooligosaccharides by entrapped dextransucrase from $4 \quad$ Leuconostoc mesenteroides B-1299. J Biotechnol 2006;124:439-445.

5 [2] Busto MD, Ortega N, Perez-Mateos M. Characterization of microbial endo-betaglucanase immobilized in alginate beads. Acta Biotechnol 1998;18:189-200.

[3] Lu Y, Zhang H, Wang L, Guo X, Yao H. A novel method for the continuous production of gamma-aminobutyric acid using immobilized rice bran. Biocatal Biotransfor 2010;28:215-221.

[4] Panesar R, Panesar PS, Singh RS, Kennedy JF. Hydrolysis of milk lactose in a packed bed reactor system using immobilized yeast cells. J Chem Technol Biotechnol 2011;86:42-46.

[5] Chien CS, Lee WC, Lin TJ. Immobilization of Aspergillus japonicus by entrapping cells in gluten for production of fructooligosaccharides. Enz Microb Technol 2001;29:252-257.

[6] Smidsrod O, Skjak-Braek G. Alginate as immobilization matrix for cells. Trends Biotechnol. 1990;8:71-78.

[7] Gomez de Segura A, Alcalde M, Plou FJ, Remaud-Simeon M, Monsan P, Ballesteros A. Encapsulation in LentiKats of dextransucrase from Leuconostoc mesenteroides NRRL B-1299, and its effect on product selectivity. Biocatal Biotransfor 2003;21:325-331. 
1 [8] Martinsen A, Storro I, Skjak-Braek G. Alginate as immobilization material: III. Diffusional properties. Biotechnol Bioeng 1992;39:186-194.

[9] Shankar SK, Praveen Kumar SK, Mulimani VH. Calcium alginate entrapped preparation of $\alpha$-galactosidase: Its stability and application in hydrolysis of soymilk galactooligosaccharides. J Ind Microbiol Biot 2011;38:1399-1405.

[10] Richetti A, Munaretto CB, Lerin LA, Batistella L, Vladimir Oliveira J, Dallago RM, Astolfi V, Luccio MD, Mazutti MA, De Oliveira D, Treichel H. Immobilization of inulinase from Kluyveromyces marxianus NRRL Y-7571 using modified sodium alginate beads. Bioproc Biosyst Eng 2012;35:383-388.

[11] Ortega N, Perez-Mateos M, Pilar MC, Busto MD. Neutrase immobilization on alginate-glutaraldehyde beads by covalent attachment. J Agric Food Chem 2009;57:109-115.

[12] Naganagouda K, Mulimani VH. Gelatin blends with alginate: Gel fibers for alpha-galactosidase immobilization and its application in reduction of nondigestible oligosaccharides in soymilk. Process Biochem 2006;41:1903-1907.

[13] Rajan A, Nair GR. Production of soya milk containing low flatulence-causing oligosaccharides in a packed bed reactor using immobilised $\alpha$-galactosidase. Int J Food Sci Technol 2010;45:2023-2031.

[14] Santagapita PR, Mazzobre MF, Buera MP. Formulation and drying of alginate beads for controlled release and stabilization of invertase. Biomacromolecules 2011;12:3147-3155. 
1 [15] Elnashar MM, Yassin MA, Moneim AEA, Bary EMA. Surprising performance of alginate beads for the release of low-molecular-weight drugs. J Appl Polym Sci 2010;116:3021-3026.

[16] Ghazi I, Fernandez-Arrojo L, Garcia-Arellano H, Ferrer M, Ballesteros A, Plou FJ. Purification and kinetic characterization of a fructosyltransferase from Aspergillus aculeatus. J Biotechnol 2007;128:204-211.

[17] Alvaro-Benito M, de Abreu M, Fernandez-Arrojo L, Plou FJ, Jimenez-Barbero J, Ballesteros A, Polaina J, Fernandez-Lobato M. Characterization of a $\beta$ fructofuranosidase from Schwanniomyces occidentalis with transfructosylating activity yielding the prebiotic 6-kestose. J Biotechnol 2007;132:75-81.

[18] Kelly G. Inulin-type prebiotics - A review: Part 1. Altern Med Rev 2008;13:315329.

[19] Rodriguez-Alegria ME, Enciso-Rodriguez A, Ortiz-Soto ME, Cassani J, Olvera C, Munguia AL. Fructooligosaccharide production by a truncated Leuconostoc citreum inulosucrase mutant. Biocatal Biotransfor 2010;28:51-59.

[20] Tungland BC. Fructooligosaccharides and other fructans: Structures and occurrence, production, regulatory aspects, food applications, and nutritional health significance. In: Eggleston G, Cote GL editors. Oligosaccharides in Food and Agriculture. Washington: American Chemical Society; 2003. 135-152. 
1 [21] Sangeetha PT, Ramesh MN, Prapulla SG. Fructooligosaccharide production using fructosyl transferase obtained from recycling culture of Aspergillus oryzae CFR 202. Process Biochem 2005;40:1085-1088.

[22] Plou FJ, Martin MT, de Segura AG, Alcalde M, Ballesteros A. Glucosyltransferases acting on starch or sucrose for the synthesis of oligosaccharides. Can J Chem 2002;80:743-752.

[23] Saulnier DM, Kolida S, Gibson GR. Microbiology of the human intestinal tract and approaches for its dietary modulation. Curr Pharm Design 2009;15:14031414.

[24] Linde D, Macias I, Fernandez-Arrojo L, Plou FJ, Fernandez-Lobato M. Molecular and biochemical characterization of a beta-fructofuranosidase from Xanthophyllomyces dendrorhous. Appl Environ Microbiol 2009;75:1065-1073.

[25] Ghazi I, Gomez de Segura A, Fernandez-Arrojo L, Alcalde M, Yates M, RojasCervantes ML, Plou FJ, Ballesteros A. Immobilisation of fructosyltransferase from Aspergillus aculeatus on epoxy-activated Sepabeads EC for the synthesis of fructo-oligosaccharides. J Mol Catal B Enz 2005;35:19-27.

[26] Csanadi Z, Sisak C. Immobilization of Pectinex Ultra SP-L pectinase and its application to production of fructooligosaccharides. Acta Aliment 2006;35:205212.

[27] Smaali I, Soussi A, Bouallagui H, Chaira N, Hamdi M, Marzouki MN. Production of high-fructose syrup from date by-products in a packed bed bioreactor using a 
novel thermostable invertase from Aspergillus awamori. Biocatal Biotransfor 2011;29:253-261.

[28] Kunamneni A, Ghazi I, Camarero S, Ballesteros A, Plou FJ, Alcalde M. Decolorization of synthetic dyes by laccase immobilized on epoxy-activated carriers. Process Biochem 2008;43:169-178.

[29] Torres-Salas P, Del Monte-Martinez A, Cutiño-Avila B, Rodriguez-Colinas B,

[34] Betigeri SS, Neau SH. Immobilization of lipase using hydrophilic polymers in the 
1 [35] Worsfold PJ. Classification and chemical characteristics of immobilized enzymes - Technical report. Pure Appl Chem 1995;67:597-600.

3 [36] Santagapita PR, Mazzobre MF, Buera, MP. Invertase stability in alginate beads: 4 Effect of trehalose and chitosan inclusion and of drying methods. Food Res Int $2012 ; 47: 321-330$

[37] Velezmoro CE, Oliveira AL, Cabral FA, Meirelles AJA. Prediction of water activity in sugar solutions using models of group contribution and equation of state. J Chem Eng Jpn 2000;33:645-653.

[38] Gosling A, Stevens GW, Barber AR, Kentish SE, Gras SL. Effect of the substrate concentration and water activity on the yield and rate of the transfer reaction of $\beta$-galactosidase from Bacillus circulans. J Agric Food Chem 2011;59:3366-3372.

[39] Laroche C, Fine F, Gervais P. Water activity affects heat resistance of microorganisms in food powders. Int J Food Microbiol 2005;97:307-315.

[40] Magnin D, Dumitriu S, Magny P, Chornet E. Lipase immobilization into porous chitoxan beads: Activities in aqueous and organic media and lipase localization. Biotechnol Prog 2001;17:734-737.

[41] Roberfroid M. Prebiotics: The concept revisited. J Nutr 2007;137:830S-837S.

[42] Rodriguez-Colinas B, De Abreu MA, Fernandez-Arrojo L, De Beer R, Poveda A, Jimenez-Barbero J, Haltrich D, Ballesteros Olmo AO, Fernandez-Lobato M, Plou FJ. Production of galacto-oligosaccharides by the $\beta$-galactosidase from 
Kluyveromyces lactis: Comparative analysis of permeabilized cells versus soluble enzyme. J Agric Food Chem 2011;59:10477-10484.

3 [43] Fernandez-Arrojo L, Plou FJ, Alcalde M, Ballesteros AO, Fernandez-Lobato M,

4 Gutierrez-Alonso P. Alginate-based immobilized biocatalyst of high operational 5 stability for the transformation of carbohydrates in continuous reactors (DALGEE's biocatalyst). Patent PCT/ES2010/070104. 2010. 


\section{$1 \quad$ Figure legends}

2 Fig. 1. Molecular structure of fructooligosaccharides (FOS) synthesized in this 3 work.

4

5 Fig. 2. SEM micrographs of the DALGEE particles. Magnifications: upper picture, $645 x$; bottom picture, $1000 x$.

8 Fig. 3. Swelling of DALGEEs obtained with Algogel 3021: (1) Alginate gel particle;

9 (2) DALGEE particle; (3) DALGEE particle after $24 \mathrm{~h}$ incubation in buffer; (4) 10 DALGEE particle after $24 \mathrm{~h}$ incubation in $600 \mathrm{~g} / \mathrm{L}$ sucrose.

12 Fig. 4. (A) Confocal image of FITC-labeled proteins, from Pectinex Ultra SP-L, 13 entrapped in DALGEE particles. The images belong to a DALGEE particle in 14 which the FITC-labelled protein solution was diluted 1:100 (v/v) prior to the gel15 entrapment procedure. (B) Proposed mechanism of protein concentration on the 16 shell of a DALGEE particle upon the drying process.

18 Fig. 5. Reuse assay of DALGEEs, containing the fructosyltransferase from

19 A. aculeatus, in successive batch reactions. After each reaction cycle $(20 \mathrm{~min})$, the 20 DALGEEs were separated from the reaction medium and washed. Reaction

21 conditions: $600 \mathrm{~g} / \mathrm{L}$ sucrose, $35^{\circ} \mathrm{C}, 900 \mathrm{rpm}$. 
1 Fig. 6. Operational stability of the fixed-bed bioreactor packed with DALGEEs

2 containing the fructosyltransferase from A. aculeatus. Reactor conditions: Feed, 600

$3 \mathrm{~g} / \mathrm{L}$ sucrose; Flow rate, $0.01 \mathrm{~mL} / \mathrm{min}$; Temperature, $35^{\circ} \mathrm{C}$.

4

5 Fig. 7. Effect of the residence time on the sucrose conversion and FOS composition

6 in the fixed-bed bioreactor packed with DALGEEs containing the

7 fructosyltransferase from A. aculeatus. Operational conditions: Feed, 600 g/L

8 sucrose; Temperature, $35^{\circ} \mathrm{C}$. 
Table 1. Effect of the source of alginate on the immobilisation by entrapment of A. aculeatus fructosyltransferase.

\begin{tabular}{|c|c|c|c|c|c|}
\hline \multirow{3}{*}{ Alginate } & Total activity before & Immobilised & Volume of & Volumetric & Immobilisation \\
\hline & immobilisation & activity ${ }^{a}$ & gel beads ${ }^{b}$ & activity $^{c}$ & yield c \\
\hline & (U) & (U) & $(\mathrm{mL})$ & $(\mathrm{U} / \mathrm{mL})$ & $(\%)$ \\
\hline SG300 & 274.0 & 138.8 & 3.4 & 40.7 & 50.7 \\
\hline Algogel 6021 & 193.6 & 34.9 & 2.4 & 14.5 & 18.1 \\
\hline Algogel 3021 & 180.9 & 46.4 & 2.3 & 20.6 & 25.6 \\
\hline
\end{tabular}

a Determined by subtracting the total initial activity in the solution prior to its gelation and the activity in the remaining $\mathrm{CaCl}_{2}$ and washing solutions.

$\mathrm{b}$ The gel-based biocatalyst volume was estimated considering a gel density of $1 \mathrm{~g} / \mathrm{mL}$.

c Theoretical values. 
Fig. 1
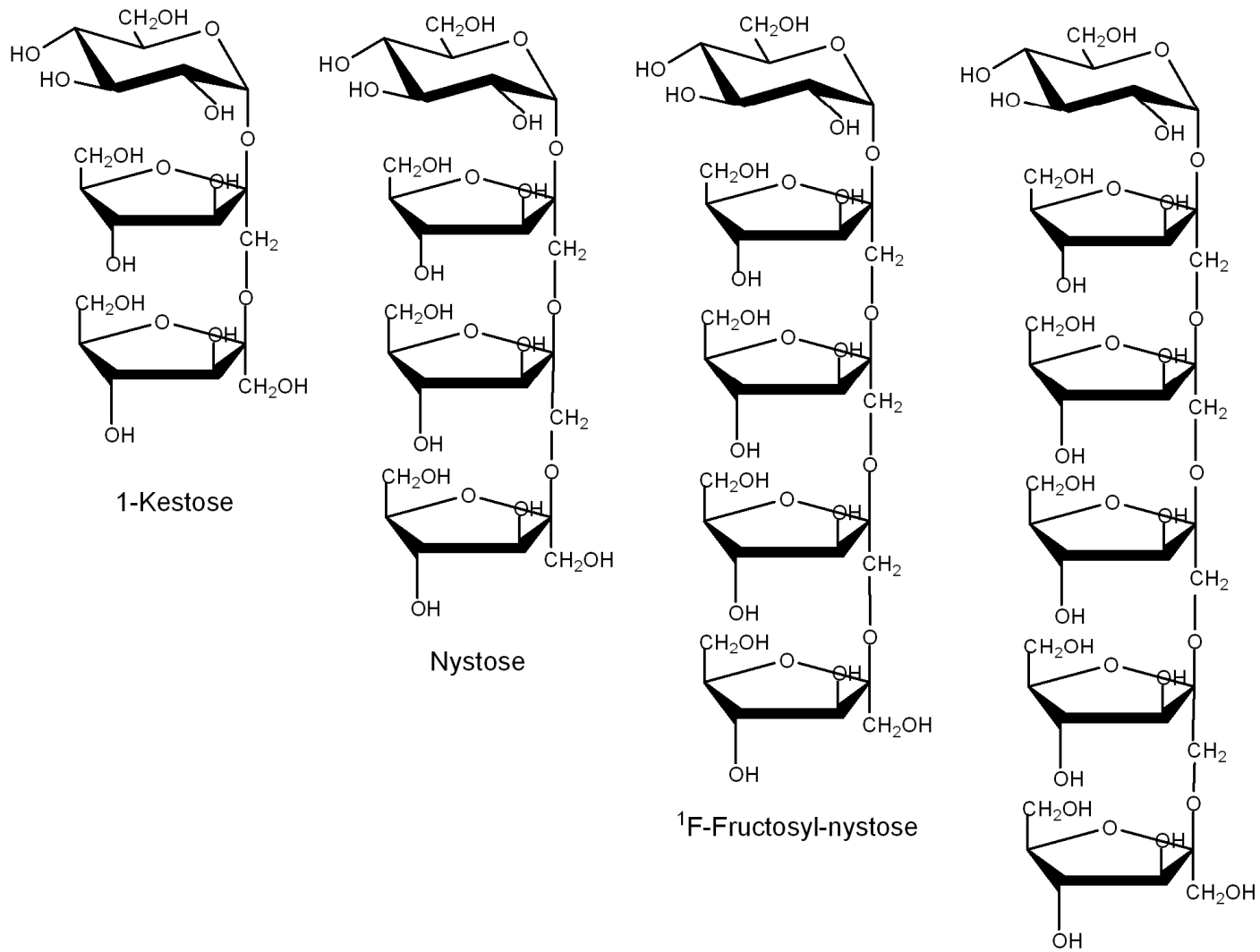

${ }^{1}$ F-Fructosyl-fructosyl-nystose 
Fig. 2
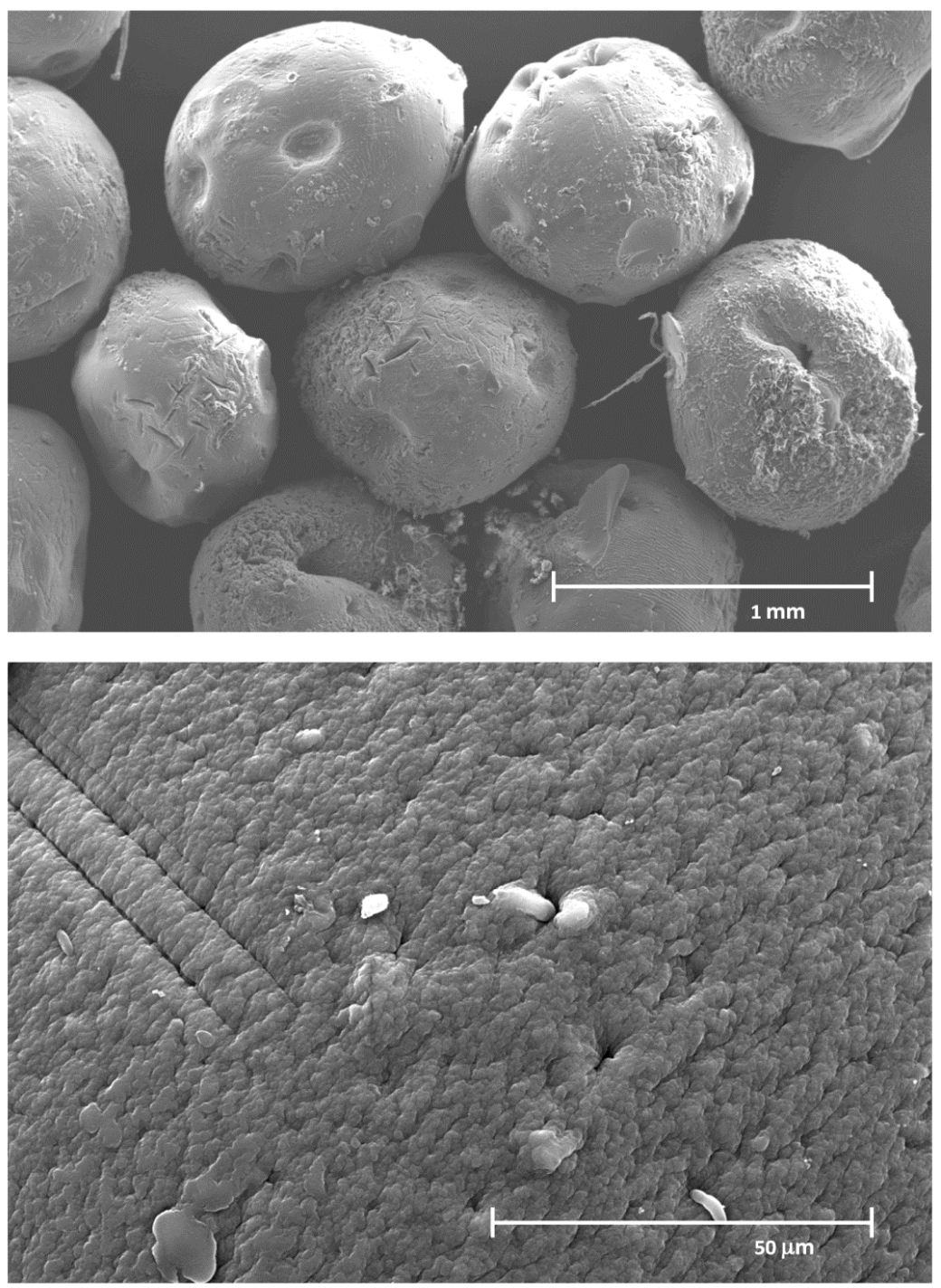
Fig. 3

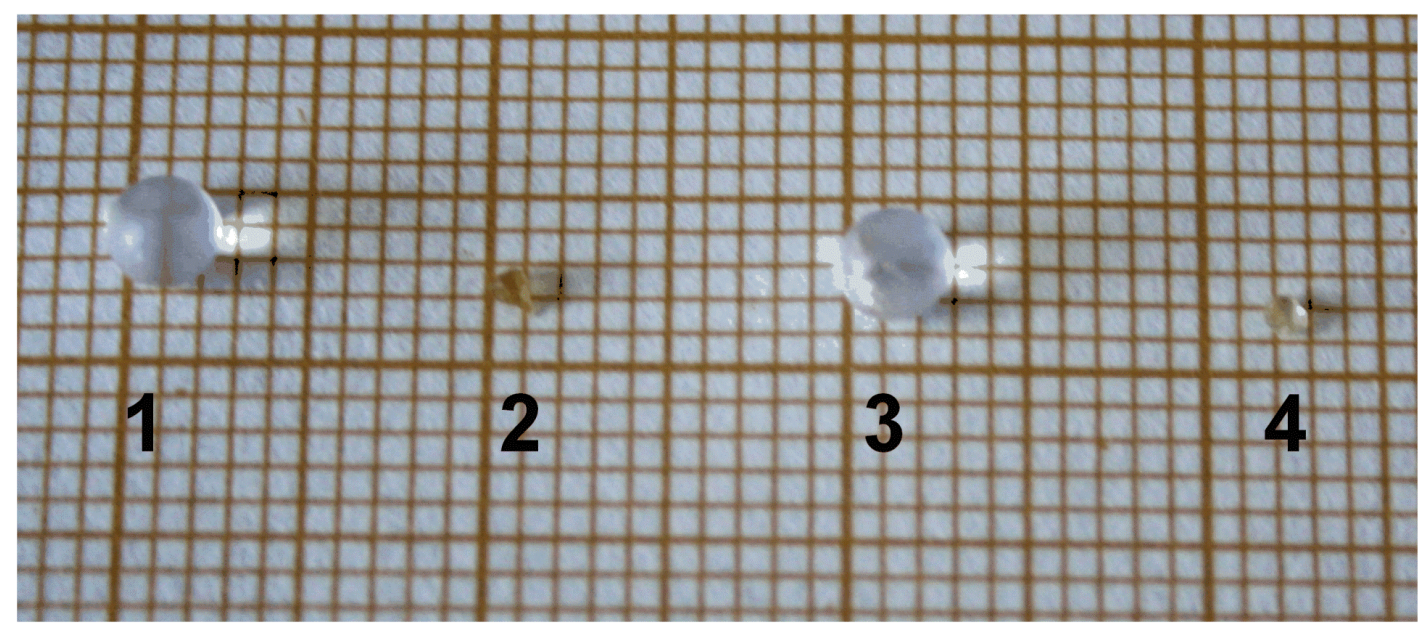


Fig. 4

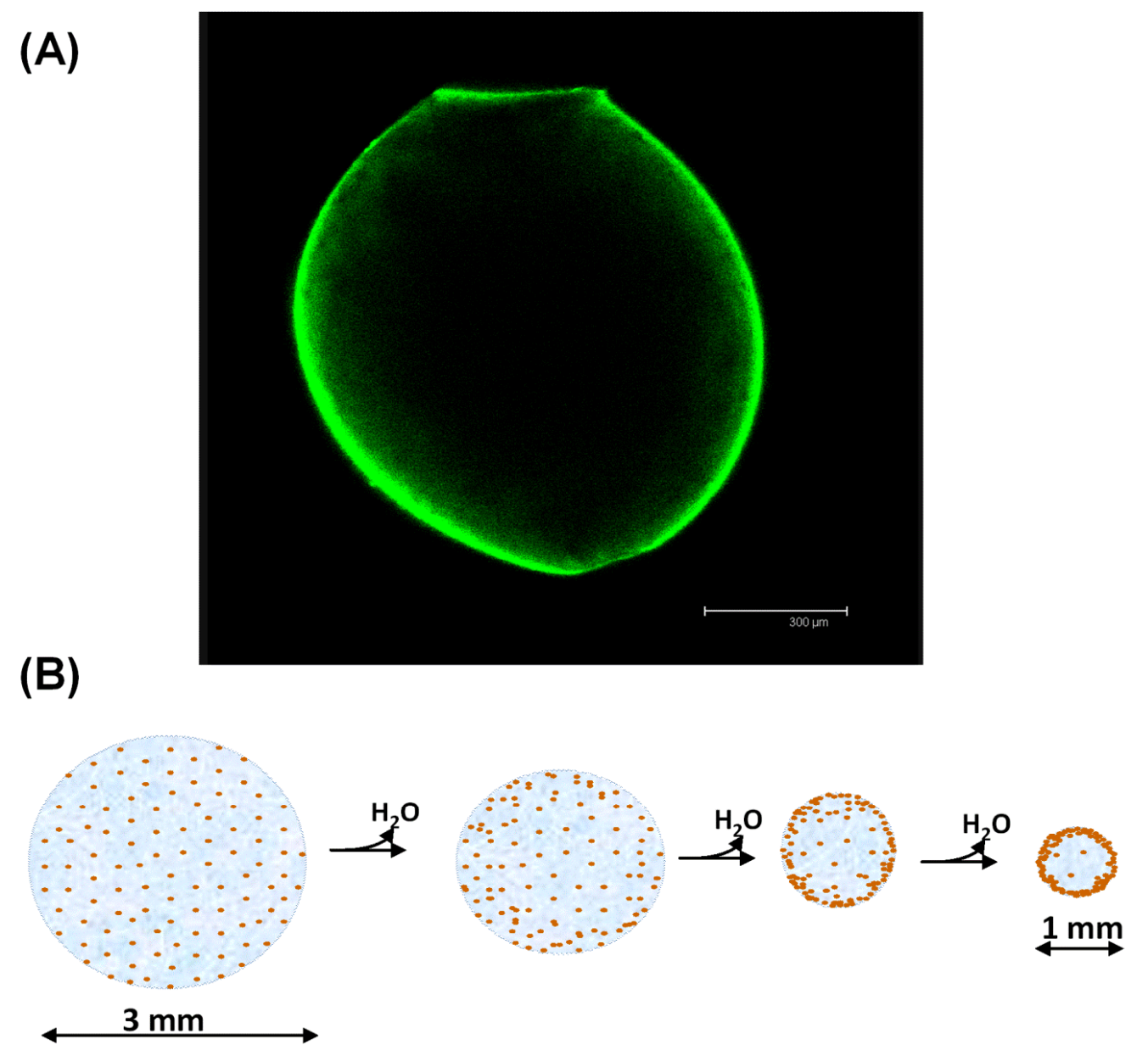


Fig. 5

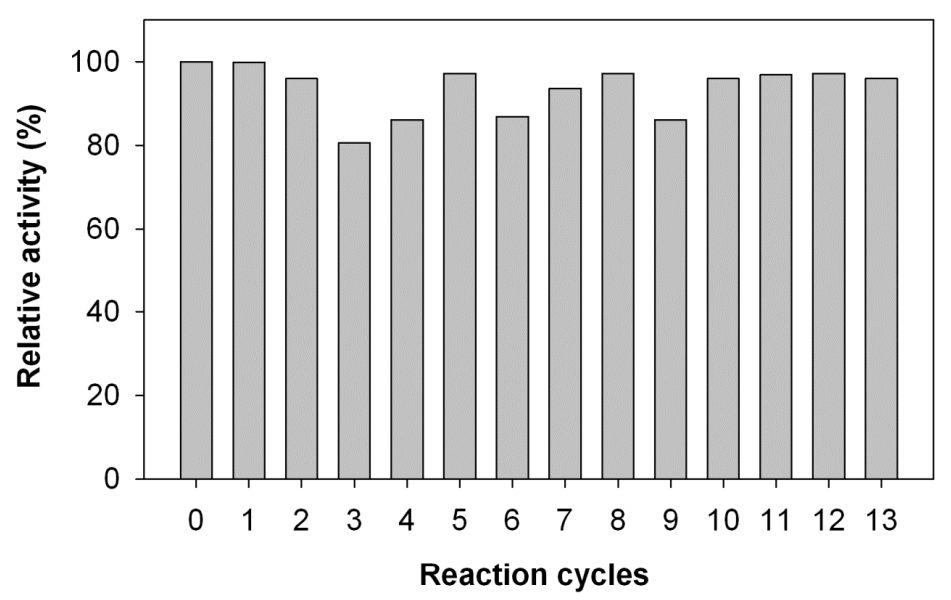


Fig. 6

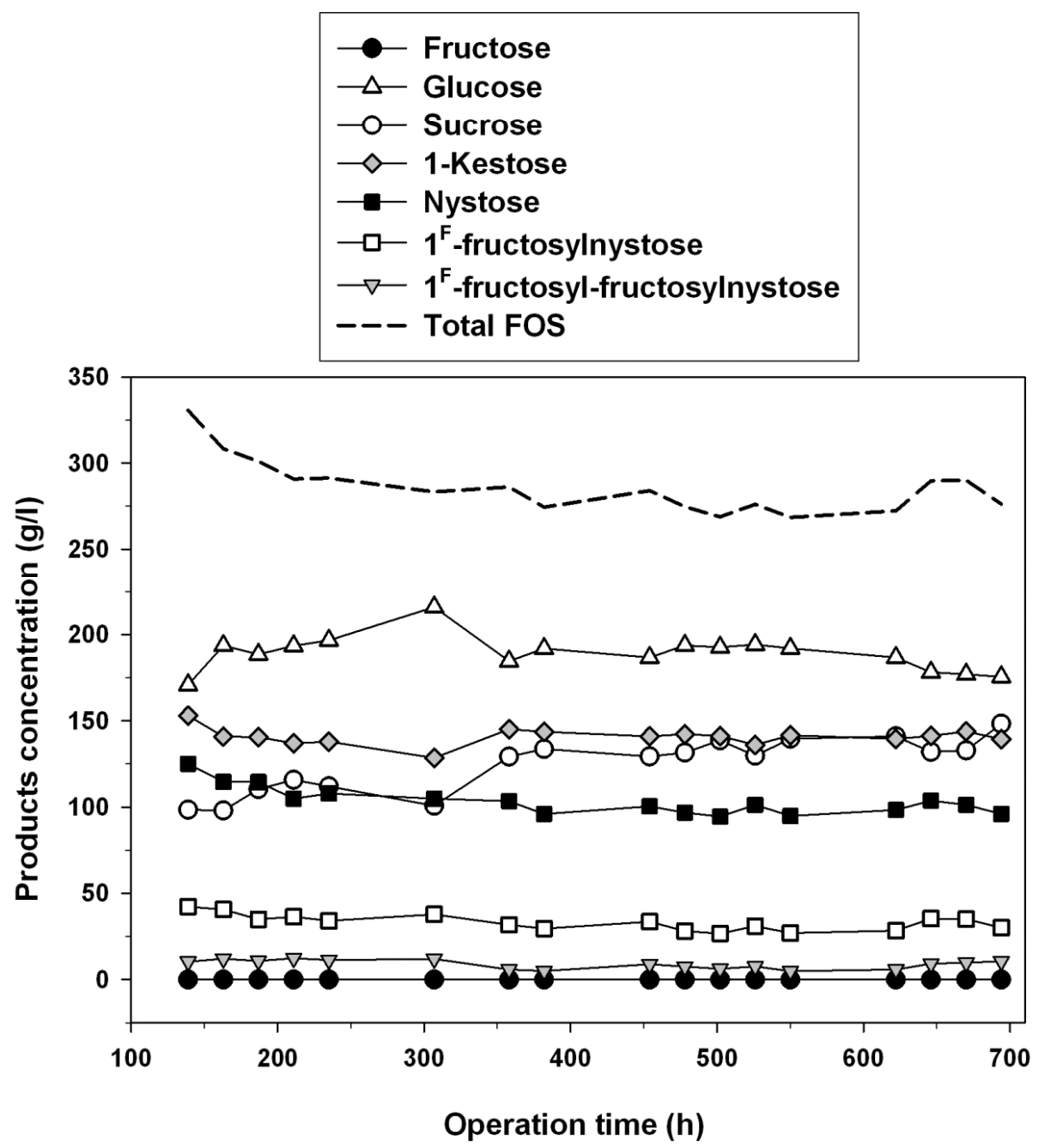


Fig. 7

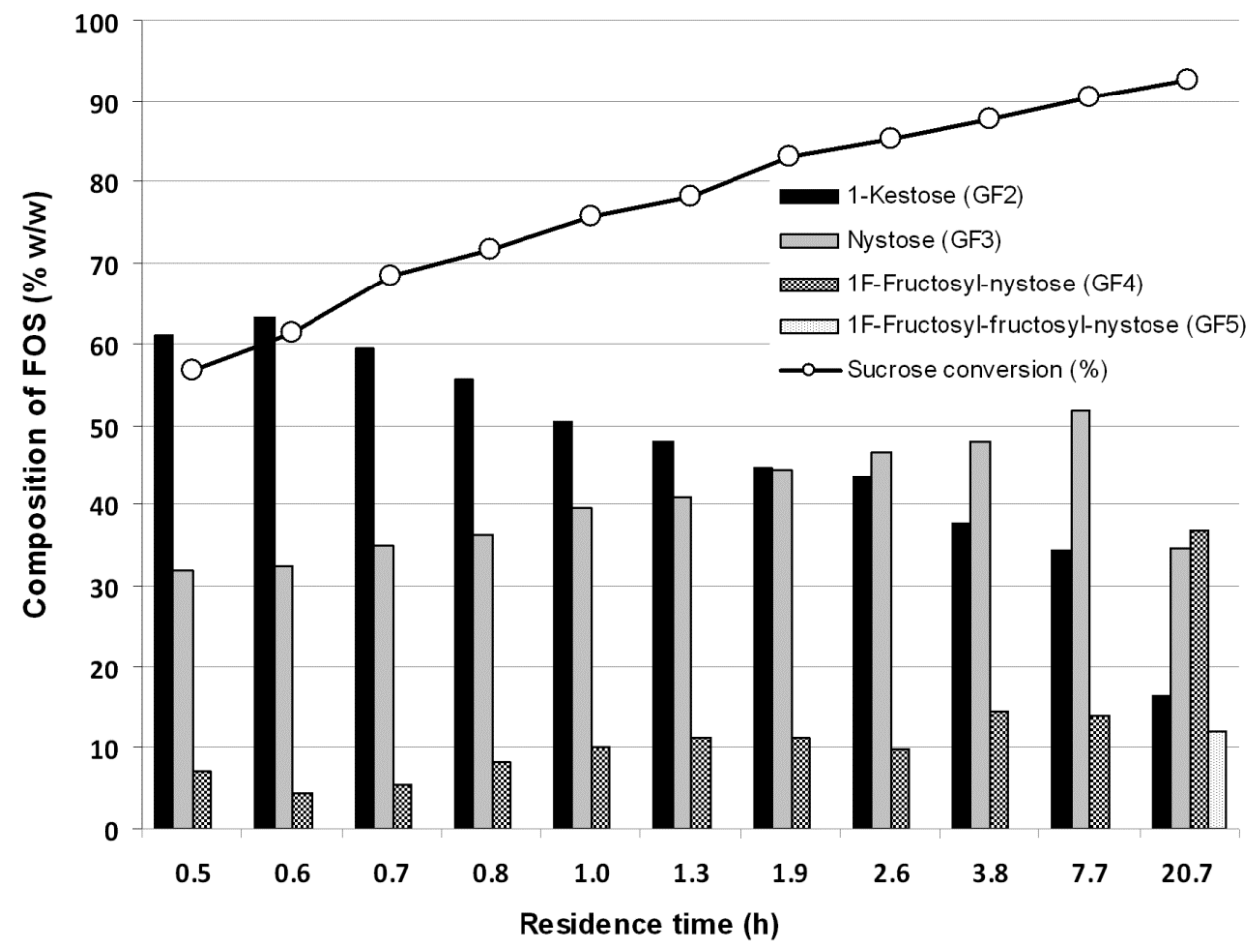

